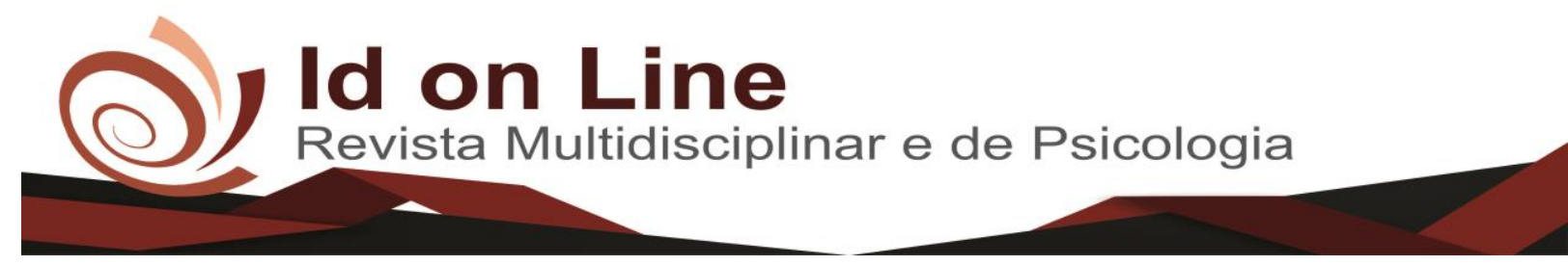

Artigo

\title{
A Importância do E-Commerce para o Processo de Compras dos Clientes da Cidade de Juazeiro do Norte
}

\author{
Francisca Alberto da Silva ${ }^{1}$; Herminig Everson Matos Queiroz ${ }^{2}$
}

\begin{abstract}
Resumo: Este presente trabalho tem o enfoque na discussão sobre o E-commerce, em que se procura apresentar aspectos relevantes no que se refere ao processo de compras online por clientes da cidade de Juazeiro do Norte CE. Dentro deste contexto, o comércio eletrônico tem se mostrando uma ferramenta de grande importância para troca de informações, transações on-line e definindo um tipo de consumidor com características e perfil específico - o E-consumidor. Por isso, o objetivo geral deste estudo foi demonstrar a importância do E-commerce para o processo de compras dos clientes localizados na cidade Juazeiro do Norte. Já os objetivos específicos intentaram evidenciar o conceito de e-commerce; identificar como funciona o processo de compras dos clientes; investigar o perfil dos consumidores, assim como as características dos clientes; mostrar os dispositivos mais utilizados para efetuar compras e o período mais utilizado pelos consumidores para efetuar transações on-line; realizar um levantamento dos principais benefícios relacionados aos clientes quando efetuam compras na internet. A metodologia da pesquisa é de natureza quantitativa, descritiva e exploratória, baseando-se na pesquisa de campo, fundamentada na opinião de uma amostragem aleatória simples de 50 consumidores, efetuada nas proximidades do Cariri Garden Shopping na cidade de Juazeiro do Norte - CE. Para instrumento de coleta de dados, foi realizada a aplicação de um questionário composto por 13 perguntas fechadas. Dessa forma, este estudo que foi efetuado tem a objeção de mostrar como resultado, se os consumidores do Município de Juazeiro do Norte - CE estão aptos a comprar on-line.
\end{abstract}

Palavras Chave: E-commerce. Processo. Cliente. Compras. Juazeiro do Norte.

\section{The Importance of E-Commerce to the Shopping Process of Customers of the City of Juazeiro do Norte}

\begin{abstract}
This work focuses on the discussion about E - commerce, in which it seeks to present relevant aspects regarding the process of online shopping by customers of the city of Juazeiro do Norte - CE. Within this context, e-commerce has proved to be a very important tool for information exchange, online transactions and defining a type of consumer with characteristics and specific profile - the E-consumer. Therefore, the general objective of this study was to demonstrate the importance of E-commerce to the customer purchasing process located in the city of Juazeiro do Norte. On the other hand, the specific objectives tried to highlight the concept of e-commerce; identify how the customer's purchasing process works; investigate the profile of consumers as well as the characteristics of customers; show the devices most used to make purchases and the period most used by consumers to carry out transactions online; perform a survey of the main benefits related to customers when they make purchases on the internet. The research methodology is quantitative, descriptive and exploratory, based on the field research, based on the opinion of a simple random sampling of 50 consumers, carried out in the vicinity of Cariri Garden Shopping in the city of Juazeiro do Norte - CE. For a data collection instrument, a questionnaire composed of 13 closed questions was applied. Thus, this study that has been carried out has the objection to show as a result, if the consumers of the Municipality of Juazeiro do Norte - CE are able to buy online.
\end{abstract}

Keywords: E-commerce. Process. Client. Shopping. Juazeiro do Norte.

\footnotetext{
${ }^{1}$ Francisca Alberto da Silva, Graduando do Curso de Administração do Centro Universitário Doutor Leão Sampaio/UniLeão - jamilyalbertosilva@gmail.com

${ }^{2}$ Herminig Everson Matos Queiroz, Professor do Centro Universitário Doutor Leão Sampaio/UniLeão, Orientador da Graduação na UniLeão - everson @leaosampaio.edu.br
}

943 Id on Line Rev. Mult. Psic. V.13, N. 43, , Supl. 1, p. 943-966, 2019 - ISSN 1981-1179

943 Edição eletrônica em http://idonline.emnuvens.com.br/id 


\section{Introdução}

Décadas atrás, as informações e o fluxo de dados, eram majoritariamente através de meios físicos, livros, documentos, escrituras e entre outros. Nos dias de hoje a tecnologia da informação revolucionou essa perspectiva, a informação é virtual, tornando-se presente em vários lugares no mesmo momento, de forma prática e acessível. Com o advento da World Wide Web, a informação ficou cada vez mais expandida e disseminada no mundo, marcada por mudanças, começando com surgimento da internet e posteriormente a utilização de computadores, estão evoluindo as formas de comércio eletrônico, com maior complexidade e funcionalidade, disponibilizando a interconexão entre produtos e serviços e os consumidores, por meio de lojas virtuais, redes sociais ou mesmo dentro de opções de comunicação que mantém os usuários conectados e informados.

O e-commerce ou comércio eletrônico é atualmente, uma forma de negócio em que os consumidores, clientes ou usuários acessam endereços eletrônicos ou plataforma on-line, para realizar transações, troca de informações e dados de maneira eficaz e específica. O comércio eletrônico é um instrumento criado a partir da internet, com o seu desenvolvimento através da grande procura de consumidores por produtos e serviços na internet, enquanto as empresas investem e intensificam investimentos nesse ramo para obter soluções econômicas, organização e atingir um número maior de público-alvo para sua marca. Esse tipo de negócio é essencial e tem como função e transmitir a nível mundial informações e características de produtos, com relação a vendas e distribuição, podendo ser considerado um sistema que engloba várias atividades inseridas na tecnologia e na forma de administração através da plataforma de e-commerce. Hoje em dia, essa forma de fazer o mercado online está modelando o cenário mundial, pois melhora os fluxos de informações, levando a internet a um patamar de grande influência para o crescimento do mercado online.

O marketing é um fator importante no ambiente empresarial e tecnológico, pois amplia negociações eletrônicas e identifica o perfil dos clientes que acessam. A internet tornou-se o mundo mais conectado, disponibilizado dados e informações através de pesquisas, daí a procura por produtos e serviços, que são direcionados a lojas virtuais, vem ganhando espaço e abrindo oportunidades para esquentar o mercado, pois haverá mais concorrência, e mais serviços sendo oferecidos, cada marca tem seu tipo de plataforma de e-commerce, onde buscam inserir e atingir seus objetivos com sucesso. Os serviços na internet, como qualquer outro serviço disponibilizado em lojas físicas, como eletrônicos, roupas, livros, mostra que a rede virtual tem corpo e forma participativa como maneira de negócios, negócios grandes como é o caso da Amazon, primeira loja virtual de livros na internet e também considerada um e-commerce de sucesso que atinge vendas e movimentações no mundo todo.

É possível destacar que o comércio eletrônico vem modificando e contribuindo para o crescimento do mercado online, visando uma melhor movimentação de bens e serviços, que dentro de um mundo globalizado é preciso mecanismos que atinjam os objetivos de forma vantajosa e eficiente para os usuários e clientes. 
Neste estudo, é possível verificar a realidade dos clientes que utilizam esse ramo de negócios para realizar transações e de todo o processo que envolve ao assumirem responsabilidade frente ao comércio eletrônico, principalmente quando se trata de uma região como o Cariri, em que o Juazeiro do Norte, que tem um potencial significativo para impulsionar a prática e-commerce devido ao seu crescimento regional e capital. Destacando-se a problemática: $\mathrm{O}$ e-commerce realmente beneficia os clientes que o-utilizam? Essa ferramenta é importante para o processo de transações em relação aos clientes? Justifica-se que a presente pesquisa busca caracterizar e definir o entendimento sobre a importância do e-commerce no processo de compras dos clientes da cidade de Juazeiro do Norte. Assim como, demonstrar quais os benefícios que os consumidores irão obter ao utilizar essa ferramenta.

Este presente trabalho é estudo que tem como objetivo geral apresentar a importância do ecommerce para o processo de compras dos clientes da cidade Juazeiro do Norte - CE. Bem como os objetivos específicos: evidenciar o conceito de e-commerce ou comércio eletrônico; identificar como funciona o processo de compras dos clientes; identificar o perfil, assim como as características dos clientes da cidade de Juazeiro do Norte; mostrar os dispositivos mais utilizados para efetuar compras e o período mais utilizado pelos consumidores para efetuar transações online; realizar um levantamento dos principais benefícios relacionados aos clientes quando efetuam compras na internet.

A metodologia da pesquisa é de natureza quantitativa, descritiva e exploratória, baseando-se na pesquisa de campo, fundamentada na opinião de uma amostragem aleatória simples de 50 consumidores, efetuada nas proximidades do Cariri Garden Shopping da cidade de Juazeiro do Norte - CE. Para instrumento de coleta de dados, foi realizada a aplicação de um questionário composto por 13 perguntas fechadas. Esta pesquisa é importante por que pode observar-se que o comércio eletrônico é relevante para o desenvolvimento do lugar onde está inserido, alavancando o crescimento do município. Dessa forma, este estudo que foi efetuado tem a objeção de mostrar como resultado, se os consumidores do Município de Juazeiro do Norte - CE estão aptos a comprar on-line.

Diante disso, o ambiente acadêmico receberá mais conteúdo e informações relevantes sobre o assunto, pois irá impulsionar os que buscam dados e aprofundamento nesse ramo de negócios, em relação ao e-commerce ou comércio eletrônico dentro da rede e suas características.

Esse trabalho irá mostrar a prática do comércio eletrônico no processo de compras on-line em Juazeiro do Norte voltadas as perspectivas de negócios, transações e trocas de informações por consumidores. O conhecimento neste caso é de tamanha importância, pois diante de um mercado globalizado e acirrado, os clientes procuram na internet, um meio de economizar e atingir os benefícios oferecidos, como também, maior comodidade e segurança no processo de compras.

\section{Referencial Teórico}

\section{O Conceito de E-Commerce}


A utilização da internet vem crescendo e influenciando na criação de novas formas de vendas de produtos e serviços, logo, surgiu o conceito de e-commerce. A primeira loja online, a Amazon, foi criada no início dos anos 90 pelo CEO Jeff Bezos, que é considerada o marco dos negócios na rede.

Nos anos 2000, o e-commerce nasceu no Brasil, na qual se define como qualquer transação realizada na rede, como também uma forma de troca de informações e dados entre empresas, consumidores e usuários. Empresas como o Mercado Livre e a Saraiva, são exemplos de redes que trabalham como e-commerce, e que alavancaram as transações entre os clientes com esse ramo de negócios. De acordo com Trepper (2000), o e-commerce ou comércio eletrônico, começou desde o começo da década de 60, mas apenas em 1994, que teve um grande acesso a equipamentos tecnológicos como computadores e a internet, e que aumentou a relação entre empresas e consumidores através de negócios e transações eletrônicas, como uma simples compra de um livro em alguma loja virtual, (ebusiness), melhorando a eficiência, rapidez e diminuição de gastos com segurança, entrega e etc., de maneira nunca antes realizada. Assim como, também, o comércio eletrônico deve ser visualizado de forma que alcance um patamar não só de uma plataforma de troca de informações e serviços ou vendas de produtos, mas também uma forma geral de negócios que geram benefícios para ambos os envolvidos e inseridos no mercado online. Para isso, é preciso uma visão mais específica e global dos tipos de transações, para que o cliente tenha várias vantagens ao utilizar essa plataforma, como a redução de custos ao cliente, trazer mecanismos para suprir as necessidades dos consumidores, tanto parte logística e distribuição, como também a adequação dos sistemas de indústrias e marketing.

Conforme afirma Limeira (apud TEIXEIRA, 2000, p.26) "Comércio Eletrônico consiste na realização de negócios por meio da internet, incluindo a venda de produtos e serviços físicos, entregues off-line, e de produtos que podem ser digitalizados e entregues on-line”. Por isso, o comércio eletrônico tem como definição a disponibilidade e competência para executar transações que envolvam troca de informações, produtos e serviços.

Para se ter um bom E-commerce é necessária uma visão mais específica e que atinja um maior nível de reconhecimento dentro do mercado, atingindo um maior número de consumidores conhecendo as características e o perfil dos mesmos. De acordo com Albertin (2004), a definição de comércio eletrônico engloba a todo os processos de que envolvem a parte financeira, marketing, geração de informações dentro ambiente online, em que não se restringe apenas a compras e vendas de produtos e serviços na rede. Dessa maneira, Albertin ainda enfatiza que a adequação e customização de produtos irão substituir as formas de comercialização em que que enfoca em produzir para depois vender da era industrial, já que com a implantação do e-commerce fará com que as empresas atendam de maneira eficiente e rápida as necessidades dos consumidores, na qual tornou-se uma estratégia de negócios.

Para um entendimento melhor do ambiente E-commerce, é preciso analisar os principais tipos e características de comércio eletrônico, pois essa temática é bem ampla e mostra-se um processo que requer o conhecimento de suas funcionalidades, o usuário pode não saber qual tipo de plataforma que utiliza, mas sabe escolher de forma minuciosa o melhor site, com faces personalizadas e fácil de utilizar, 
já que a atração dos clientes dentro de uma loja on-line, é um desafio, porém, quando este ambiente é vantajoso para os usuários, os mesmos irão retornar outras vezes, mesmo que os valores de produtos e serviços sejam maiores que em outros sites.

Do ponto de vista técnico, conforme afirma Albertin, o comércio eletrônico (apud TEIXEIRA, 2000, p.48), é subdividido em quatro classes, de acordo com sua aplicabilidade: B2C (negócio-aconsumidor), B2B (negócio-a-negócio), intranet (intra-organizacional) e B2G (negócio-a-governo). Outras etapas do e-commerce têm-se o consumidor-a-consumidor (C2C) e consumidor-a-empresas (C2B), é definida como parte do ramo E-business. O quadro abaixo, identifica-se os componentes financeiros dos processos de atividades online: governo, empresas e consumidor, quando em relação as aplicabilidades do E-commerce e E-business:

Quadro 1 - Componentes financeiros e suas aplicabilidades.

\begin{tabular}{|c|l|l|l|}
\hline & \multicolumn{1}{|c|}{ Governo } & \multicolumn{1}{c|}{ Empresas } & \multicolumn{1}{c|}{ Consumidor } \\
\hline Governo & $\begin{array}{l}\text { G2G Coordenação (E- } \\
\text { business) }\end{array}$ & $\begin{array}{l}\text { G2G Informação (E- } \\
\text { business) }\end{array}$ & $\begin{array}{l}\text { G2C Informação (E- } \\
\text { business) }\end{array}$ \\
\hline Empresas & B2G Aquisiç̧ões (CE) & B2B Comércio (CE) & B2C Comércio (CE) \\
\hline Consumidor & C2G Pagamentos de & C2B Comparação de & C2C Leilōes de \\
& Taxas (E-business) & Preços (E-business) & Mercadorias (CE) \\
\hline
\end{tabular}

Fonte: Albertin (apud TEIXEIRA, 2000, P. 48)

O comércio eletrônico também inclui relações business to business (B2B) que transformas as compras mais simples para as maiores empresas. De acordo com Kotler (2000, p. 681):

\begin{abstract}
O termo e-commerce descreve uma ampla variedade de transações eletrônica, como envio de pedidos de compra para fornecedores via EDI (troca eletrônica de dados), o uso de faz e e-mail para conduzir transações; o uso de caixas eletrônicas e cartões magnéticos para facilitar o pagamento e obter dinheiro digital, assim como o uso da internet e de serviços on-line.
\end{abstract}

O e-commerce vem sendo importante tema de estudos e regulamentações. Pois o Ministério Público Federal disponibilizou diretrizes e especificações para comércio eletrônico no Brasil no início de 2010. Esse documento tem a função de colaborar com a implementação nos planos jurídicos no quesito segurança para o e-commerce no país, dando confiança aos e-consumidores.

\title{
Crescimento do E-Commerce
}

A atuação do comércio eletrônico vem ganhando cada vez mais espaço no mercado em geral, pois, no Brasil, em 2010, atingiu a marca de bilhões em faturamentos nessa plataforma, e atualmente 
deve seguir apresentado crescimento maior do que nos últimos anos. Segundo dados da E-bit é previsto um crescimento de mais de $35 \%$, em relação ao primeiro semestre do ano, e espera-se que este ramo gire em torno de mais de 6 bilhões de reais, conforme o gráfico mostra abaixo.

Gráfico 01 - Crescimento do Faturamento $1^{\circ}$ Semestre

em milhöes de Reais

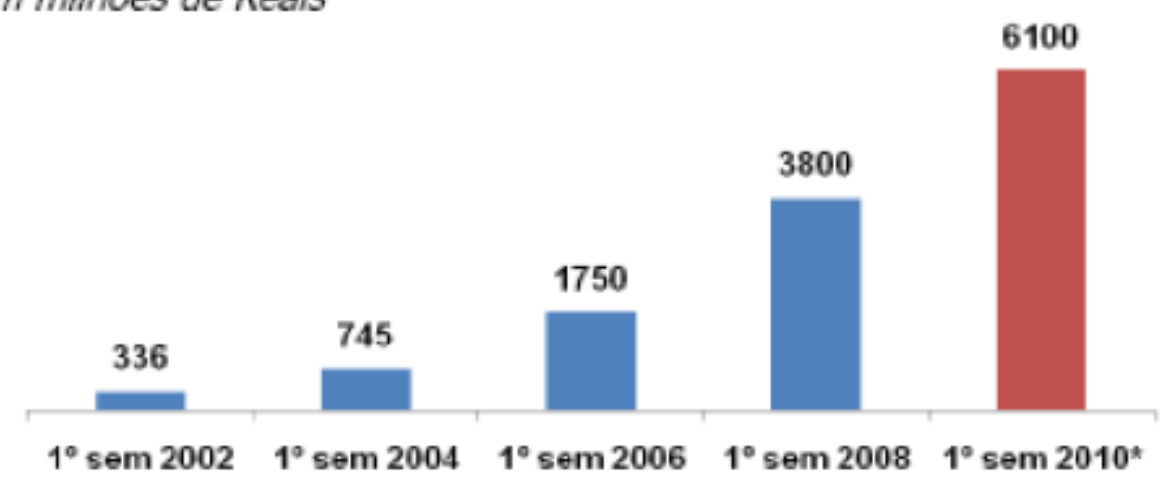

Fonte: E-bit, 2010.

A E-bit também afirma, que atualmente mais de 50 milhões já compram pela internet, na busca de melhores ofertas, opções, diferentes maneiras de pagamento e de bens e serviços de qualidade. Outro aspecto relevante que influenciou o crescimento do comércio eletrônico foi a confiança do mercado e dos consumidores, em atenção especial ao cliente e sua comodidade.

Gráfico 02 - Crescimento de e-consumidores (em milhões)

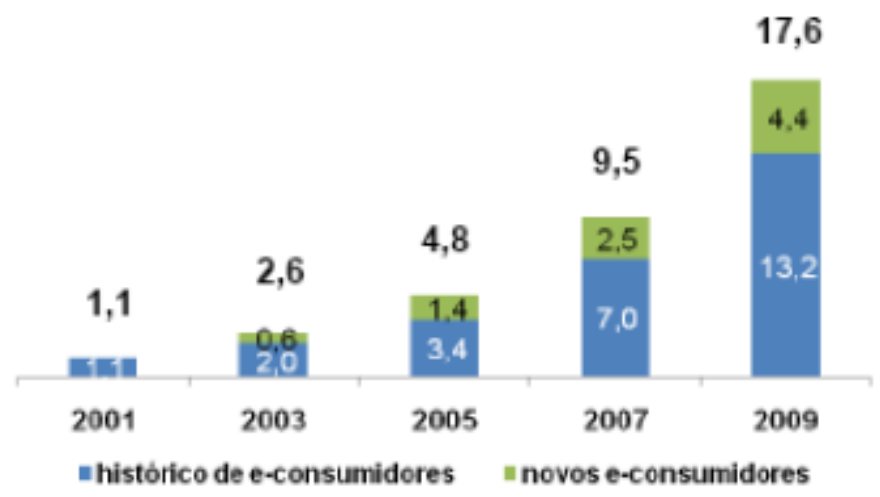

Fonte: E-bit, 2010.

De acordo com os dados, há um crescimento elevado de usuários da internet que realizam compras, com alguns tipos de negócios ganhando frente ao comércio eletrônico, que são: Livros; assinaturas de Apps de vendas de produtos: revistas; medicamentos e estética; informática e eletrônicos 
e eletrodomésticos, no viés em que o Governo impõe medidas para diminuição de impostos e liberação de crédito para os empreendedores do e-commerce e principalmente os consumidores. O parcelamento das compras dos produtos foi outro aspecto que alavancou as compras online, pois pagar integralmente o valor de um produto na maioria das vezes se torna algo complicado para o consumidor, mas poder parcelar em até 24 vezes em algumas lojas online no cartão de crédito é um fator impulsionador para atrair um maior número de clientes.

Em 2014, segundo o relatório Webshoppers o e-commerce no Brasil arrecadou quase 36 bilhões de reais, 24\% maior que em 2013. E em relação aos pedidos na internet, no mesmo ano, registrou-se 103,4 milhões, 17\% maior que em 2013. Também em 2014, mais de 51,1 milhões de consumidores realizaram ao menos uma compra online, tendo uma grande atração de novos consumidores e maior número de pedidos.

Um fator que contribui para o crescimento das transações na rede é quantidade de horas que os usuários acessam a internet, os brasileiros assistem menos televisão e recorrem as redes sociais e internet, daí um maior contato com propagandas, informações e dados, já que $51 \%$ da população brasileira utilizam internet, ou seja, mais da metade dos brasileiros.

\section{Benefícios ao Consumidor e as Empresas do Comércio Eletrônico}

Os benefícios aos consumidores são diversos, porém variam de acordo com o tipo de Ecommerce que o mesmo está inserido ou acessa quando vai efetuar compras, pois, há várias plataformas e lojas on-line que oferecem diversos incentivos e promoções que atraem a clientela, formulando um público-alvo, assim como, identificando o perfil dos usuários para criar mecanismos de marketing para atingir um contingente maior.

Entretanto, o consumidor imerso neste ambiente, ele terá mais opções de escolha ao realizar compras de produtos e adquirir serviços, recebendo descontos, mais credibilidade, formas diferentes de pagamento, segurança no processo de compra, informações precisas e atualizadas dos produtos e com preços acessíveis, além da comodidade do usuário realizar esse processo em casa sem precisar deslocar até uma loja física. Segundo Andrade (apud TEIXEIRA, 2000, p. 32-33), o e-commerce traz consigo benefícios para os envolvidos, tanto para as empresas tanto para os consumidores. Alguns como: novos tipos de produtos, dados e informações sobre o produto; proporcionar compras mais eficientes com mais alternativas, formas de pagamentos, preços mais acessíveis, qualidade dos bens e serviços automatizados, como também o aumento da concorrência entre os vendedores e varejistas e um acesso melhor aos produtos por um bom preço. Logo, observa-se que o e-commerce é realmente uma ferramenta que pode ajudar no cotidiano dos usuários, servindo de mecanismo para suprir necessidades como deslocamento, desenvolvimento socioeconômico, acesso a informações de produtos e serviços de forma instantânea e etc. 
Já o processo de beneficiamento para empresas que são próprias plataformas da internet que influenciam diretamente na forma de comprar do consumidor, segundo Albertin (apud TEIXEIRA, 2000, p. 36) o e-commerce transforma de maneira simples a entrada de produtos e serviços no mercado, independentemente do ramo de negócios, possibilitando estabelecer a inserção de produtos substitutos. Tendo acesso a essa plataforma, o consumidor terá acesso a variados aspectos que auxiliam no momento das compras, como novos itens de estoque, tabela de preços, introdução de novos produtos, agilizando, dessa forma, as vendas e aumentando a recepção e aceitabilidade dos clientes.

Para o usuário, dito consumidor da internet, é como qualquer outro consumidor de uma loja física, com direitos e deveres em Lei, logo, é necessário verificar os itens de obrigações de empresas que dispõem de serviços para estes consumidores on-line. Para Kotler (1999, p. 200) alguns aspectos se fazem importantes para os empreendedores em detrimento o bem estar dos clientes: a) Expandir o alcance do mercado; Gerar visibilidade; Fortalecer o relacionamento nos negócios; Poder de resposta; Oferecer novos serviços; Redução de custos; Evitar perdas financeiras e Estoque Just in Time - quando preços em altas, se faz necessário reduzir os gastos operacionais, fazendo com que reaja mais rápido a demanda, contudo, é preciso também diminuir o estoque para adequar-se de forma explícita e vantajosa ao preceitos do cliente.

\section{E-Marketing}

A escolha da plataforma de e-commerce é uma das etapas mais importantes do processo de implantação do comércio eletrônico como forma de alavancar os negócios e transações das empresas. Quando se relaciona a ação de começar uma web loja, há muitos aspectos e itens a serem levados em consideração. Essa escolha da plataforma, é essencial nesse estágio inicial, e prevenir e desviar problemas que levariam a optar por mudança tempos depois. Pois, causaria problemas financeiros, de adequação, contabilidade e faturamento. Levando em conta isso, é preciso ter uma análise crítica, organizada dos fatores importantes dessa temática para empresas e consumidores como maneira de viabilizar a plataforma para negociações e transações entres os mesmos atualmente no Brasil, já que é um mercado altamente lucrativo, tecnológico e passivo de várias adequações para se encaixar no ramo de atuação dos varejistas. De acordo com Limeira (apud TEIXEIRA, 2000, P. 51) e-marketing "é o conjunto de ações de marketing intermediados por canais eletrônicos como a internet, em que o cliente controla a quantidade e o tipo de informação recebida". Afirma, ainda, que " com a evolução da tecnologia da informação e da comunicação, especialmente a "internet", o marketing interativo evoluiu para o chamado marketing eletrônico ou e-marketing [...] intermediadas por canais eletrônicos como a internet."

Dentro do mundo globalizado atualmente, a maioria dos negócios tem requisitos específicos, e é por isso à necessidade de se optar de forma correta a solução mais vantajosa para o seu tipo de trabalho 
online. Porém, para que isso ocorra de forma graduada e lucrativa, alguns itens básicos devem estar inseridos em qual seja a plataforma de e-commerce. Segundo Kotler (apud TEIXEIRA, 2000, P.51) “ no e-marketing o consumidor, não o promotor de marketing, dá permissão e controla a negociação". De forma que haja a adequação ao ambiente global do mercado online, em que o foco das empresas e plataformas on-line devem ser direcionadas para um marketing efetivo, com o enfoque total ao cliente.

Conforme afirma Luciana Lamounier (2010), o e-commerce tem como consequência de sua implantação e utilização a automatização dos processos de transações, transformando-se mais interessantes e liberando as empresas a relacionarem com as outras e com seus clientes e usuários. A internet auxilia e intensifica a troca de informações, dados e vários itens que transformam alguns aspectos para melhor no cotidiano dos usuários, como facilitar a identificação de compradores em decorrência dos que se destacam no mercado, as informações ocorram de maneira eficiente e segura e a identificação dos fornecedores e produtos corretos e de qualidade.

Dessa forma, a globalização e o surgimento das novas tecnologias trazem como consequência a necessidade de profissionais de marketing interajam e reanalisem as maneiras dos processos aos que trabalham, se comunicam e passam informações para o consumidor, tendo, dessa forma, uma oportunidade de obter mais habilidades e conhecimento no gerenciamento de clientes.

\section{Atuações do E-Commerce no Mercado}

O e-commerce está atuado em vários segmentos no mercado. Logo, procurou-se compreender, em que essa ferramenta no cenário atual na cidade de Juazeiro do Norte. Na observação do site Ecommerce.org (2013), é a de que os consumidores têm semelhanças em relação a características no tocante ao público-alvo do comércio eletrônico, independentemente do segmento de e-commerce ou plataforma implantada na empresa. Entretanto, nessa perspectiva, para os clientes que acessam um site para realizar uma compra de um produto, acaba por conhecer e obter informações de outros produtos e serviços, representando um interesse maior de procura dentro da rede. O site também pode personalizar sua forma de vendas e disponibilização de seus produtos, já que tem clientes assíduos e segmentados, aplicando-lhes ao público-alvo maior número de informações e conteúdo, causando-lhes impacto maior na hora de fechar as compras. Por isso, é necessário que o Empreendedor esteja informado e inserido ao perfil dos clientes e do negócio que irá desenvolver.

Segundo o site E-commerce.org (2013), a maioria das empresas de grande porte tem influência no poder de compra dos consumidores, devido a sua adequação e credibilidade adquirida no decorrer do tempo de sua atuação, como também a grande quantidade de transações que lhe traz possibilidade de obtenção de melhor custo-benefício, permitindo-lhe passar para o consumidor um produto com valores menores, qualidade e usabilidade duradoura, dependendo do tipo de produto, já que são com comercializadas na internet desde de produtos orgânicos a duradouros e também os de obsolência 
programada. Sendo que, por necessidade de acompanhar o mercado, surgem características heterogêneas em algumas empresas, levando um período maior para se adequar a forma de troca de informações e principalmente da tecnologia, pois, atualmente, é de extrema necessidade as empresas, implantarem softwares para gerenciar e auxiliar na administração da forma de negócios, inclusive no tocante ao comércio eletrônico, em que a maioria do processo é majoritariamente online. Em contrapartida, há empresas que já estão adaptadas a esse modelo de gerenciamento e usabilidade da tecnologia, e conseguem acompanhar os segmentos do mercado online, pois o público-alvo tem uma base de informação da empresa e apresenta uma ligação acentuada e mais homogênea entre ambos.

Para Books (1993), os pontos de atuação de mercado devem ser direcionados primordialmente aos clientes, pois, o grande sucesso de uma loja virtual é conseguir manter o direcionamento nos atributos e necessidades dos consumidores e não apenas no produto. É obrigação da empresa, a identificação das necessidades do seu público-alvo, para poder dispor de um produto com similaridade e com características intrínsecas aos clientes.

É indubitável o aprofundamento do conhecimento da empresa que trabalha com e-commerce sobre o consumidor que está inserido no seu plano de negócios online, assim como suprir as necessidades com especificidades dos clientes é um diferencial para se obter uma boa relação, podendo contribuir para os benefícios do e-consumidor. Dessa forma, a organização atinge melhores resultados, causando uma maior aceitabilidade do produto e serviço disponibilizado, adquirindo dos clientes uma provável fidelidade prolongada.

De acordo com Books (1993), quando a empresa online, plataforma e-commerce ou outro segmento do comércio eletrônico, oferta a venda de produto/serviço pela rede, não condiz ser uma ação simplista e fácil, pois requer diversos aspectos, e principalmente relacionados aos clientes, pela decorrência do excesso de concorrência e queda em preços de alguns produtos, como também, é preciso um olhar inovador e corajoso para seguir dentro do mercado competitivo, para que depois, obtenha resultados e lucros dos investimentos aplicados. Porém, quando os consumidores dão atenção e crença no que está sendo vendido pela empresa, logicamente a empresa realizará um maior número de vendas não se restringindo ao valor do preço ofertado. Logo, o objetivo é inicialmente formular e construir um valor para a marca e depois repassar confiança e qualidade ao público alvo.

Em confronto com as afirmações do autor Books, podemos observar a mesma observância por Adolpho (2013) em que reflete dentro do meio digital, onde a empresa deve realizar a personalização de sua página ou loja na internet direcionada majoritariamente ao público alvo em conjunto com o conteúdo informacional - parte escrita - demonstrando vários itens e informações do produto, como também os textos que auxiliam a fazer o escopo da definição do próprio texto, gerando transações e realizando a objetividade de uma loja online. 


\section{Metodologia}

A pesquisa foi desenvolvida no município de Juazeiro do Norte - CE direcionada em conhecer as perspectivas, bem como a importância do E-commerce no processo de compras dos clientes. Para se obter um maior conjunto de informações e um melhor entendimento deste estudo, foi realizada uma pesquisa em artigos técnicos, periódicos e teses para se obter conhecimento e um cenário atual do ecommerce, analisando os principais aspectos desse ramo de negócios em relação a compras realizadas por clientes ou consumidores. Em relação a abordagem, a pesquisa é de natureza quantitativa, descritiva e exploratória. De acordo com a aspecto de sua abordagem, pesquisa quantitativa é um método de pesquisa social que utiliza a quantificação nas modalidades de coleta de informações e no seu tratamento (MICHEL, 2005). Descritiva e exploratória preocupa-se em observar os fatos, registrá-los, analisá-los, classificá-los e interpretá-los sem interferir nos resultados (ANDRADE, 2002).

Na sequência foi realizada uma pesquisa de campo, fundamentada na opinião de uma amostragem aleatória simples de 50 consumidores, efetuada nas proximidades do Cariri Garden Shopping da cidade de Juazeiro do Norte - CE, onde foi realizada a aplicação de um questionário composto por 13 perguntas fechadas. O município de Juazeiro do Norte é uma cidade que é constituída por pessoas que buscam meios e mecanismos práticos para suprirem suas necessidades, custo-benefício e entre outros. Por isso, o levantamento dos dados foi voluntário por parte dos investigados da pesquisa, onde os integrantes foram abordados, compreenderam a temática da pesquisa, tendo a livre escolha de responder ou não ao questionário, porém, quase todos os abordados participaram. A pesquisa foi realizada no mês de outubro, em datas distintas, seguindo o fluxo de pessoas e a disponibilidade, mas todas ocorreram no período da tarde. Após a coleta de dados foi realizado o tratamento através de planilhas do Microsoft Excel, gerando gráficos e tabelas apresentadas neste artigo.

\section{Análise dos Dados}

Considerando os aspectos do E-commerce. Este trabalho mostra os resultados obtidos em campo em relação a importância do e-commerce para o processo de compras dos clientes na cidade de Juazeiro do Norte-CE. Somando a pesquisa, foi investigado informações pertinentes ao estudo, como características do processo de compra, bem como o perfil dos investigados. A pesquisa abaixo foi caracterizada pela aplicação de 13 questionários para uma amostragem de 50 pessoas, em que que buscou informações e dados sobre as práticas do e-commerce pelos consumidores em contraposto as atividades relacionadas a compras, transações on-line, troca de informações e entre outros itens que impactam o cotidiano da sociedade local de variadas maneiras.

Nesse contexto, procurou-se analisar a faixa etária dos investigados, com o objetivo de identificar o impacto do e-commerce na cidade de Juazeiro do Norte em relação aos consumidores ou 
clientes que utilizam essa ferramenta. Os dados foram analisados de acordo com a pesquisa de campo efetuada, sendo representada abaixo no Quadro 2.

Quadro 2 - Faixa etária, Escolaridade e Gênero.

\begin{tabular}{|l|l|l|}
\hline Faixa etária & Escolaridade & Gênero \\
\hline $11 \%-18-24$ anos & $6 \%$ - Ensino Superior & $53 \%$ Masculino \\
\hline $23 \%-25-39$ anos & $25 \%$ - Superior incompleto & $47 \%$ Feminino \\
\hline $31 \%-40-59$ anos & $27 \%$ - Médio completo & \\
\hline $35 \%$ - acima de 59 anos & $11 \%$ - Médio incompleto & \\
\hline & $13 \%$ - Fundamental completo & \\
\hline & $18 \%$ - Fundamental incompleto & \\
\hline
\end{tabular}

Fonte: Dados da Pesquisa (2018).

Tendo em vista, a análise de informações iniciais da pesquisa, a faixa etária da maioria dos participantes é de (35\%) para pessoas acima de 59 anos. Uma porcentagem considerável dos investigados possui curso superior incompleto $(25 \%)$, já os que possui ensino médio completo tem um contingente de (27\%). Em relação ao outro aspecto vislumbrado, o gênero é distribuído entre (53\%) de consumidores do sexo masculino e (47\%) do sexo feminino. De acordo com os números de ambos dos consumidores, mostra-se quase que igualdade de utilização da internet de ambos os gêneros, sendo que ultimamente as mulheres estão cada vez mais dando ênfase a esse meio e consequentemente seu crescente número nessa temática.

Outro aspecto importante que foi aplicado no questionário aos investigados, era o item renda mensal, pois é preciso compreender a faixa de renda da população, com o propósito de investigar se eles tinham um poder aquisitivo baixo, médio ou alto para efetuar transações online. Como está representado no gráfico 3.

Gráfico 3 - Renda mensal dos investigados
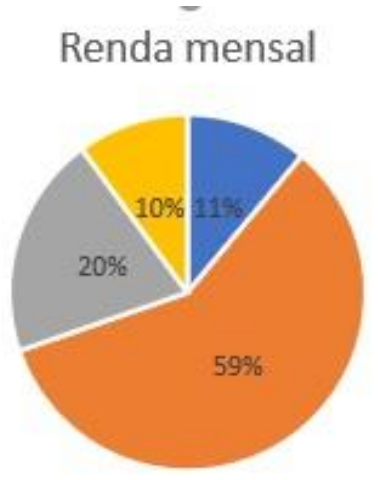

- Até 1000,00 p/mês

- De RS 1000,00 a 2000,00 p/mês

= De RS 2000 a RS 4000 p/mês

= Acima de RS 5000,00 p/mês

Fonte: Dados da pesquisa 
Com relação a renda mensal dos investigados da cidade de Juazeiro do Norte, (59\%) tem renda que varia entre 1 mil a dois mil reais ao mês, (20\%) entre dois mil a quatro mil, (11\%) até mil reais e somente $(10 \%)$ possui renda acima de cinco mil reais. Dessa forma, pode-se observar que um grande contingente da amostragem deste trabalho em relação a renda dos mesmos, majoritariamente são consumidores com renda que vão até quatro mil reais.

Dentro do contexto abordado anteriormente, foi perguntado ao grupo sobre a frequência de utilização da internet, com o objetivo de investigar o período que os usuários acessam diariamente as redes sócias, aplicativos, endereços eletrônicos e etc., conforme mostrado no gráfico 4.

Gráfico 4 - Frequência de utilização da internet pelos investigados.

\section{Período de Utilização da Internet diariamente}

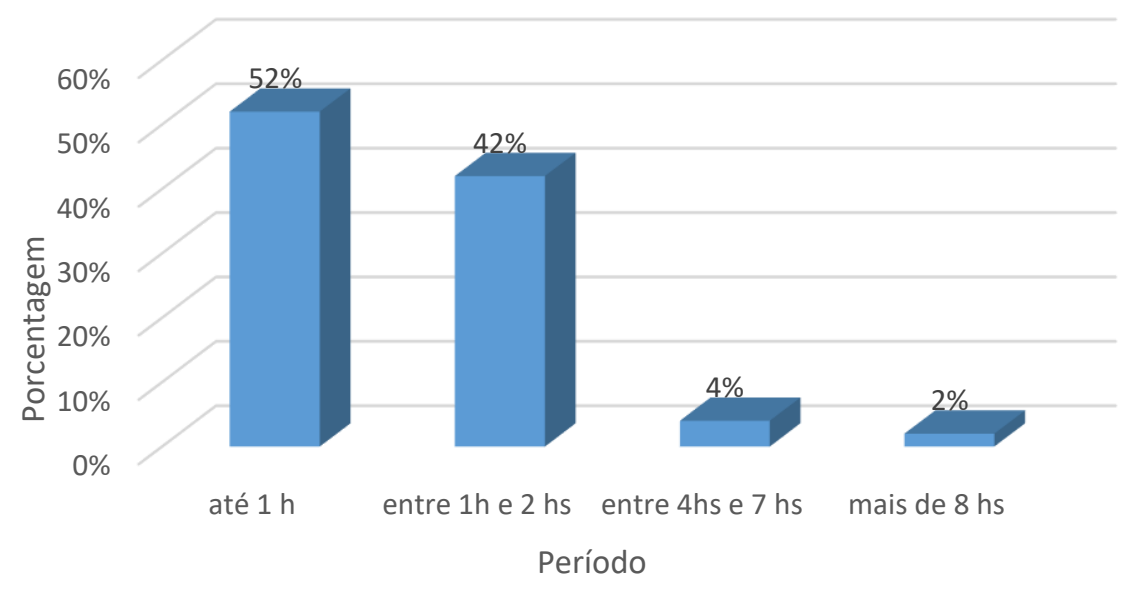

Fonte: Dados da pesquisa.

No período de até 1 hora, é o que detêm do maior contingente de usuários (52\%), para o período entre 1 hora e 2 horas de utilização, (42\%) das pessoas acessam a internet. Já para o período entre 4 horas e 7 horas, apenas (4\%) dos investigados passam esse tempo na internet. E por fim, o menor percentual é para o período de mais de 8 horas, em que somente $2 \%$ das pessoas investigadas ficam esse período na rede.

Para uma análise mais aprofundada das características e costumes dos investigados, foi perguntado a amostragem qual rede ou plataforma mais acessada no cotidiano quando acessa a internet, com o objetivo de verificar o perfil das buscas efetuadas pelos os usuários, assim como identificar as redes com mais status de acesso em maior frequência. Conforme mostrado no gráfico 5. 
Gráfico 5 - Rede ou plataforma mais acessada.

\section{Rede ou plataforma mais acessada no cotidiano}

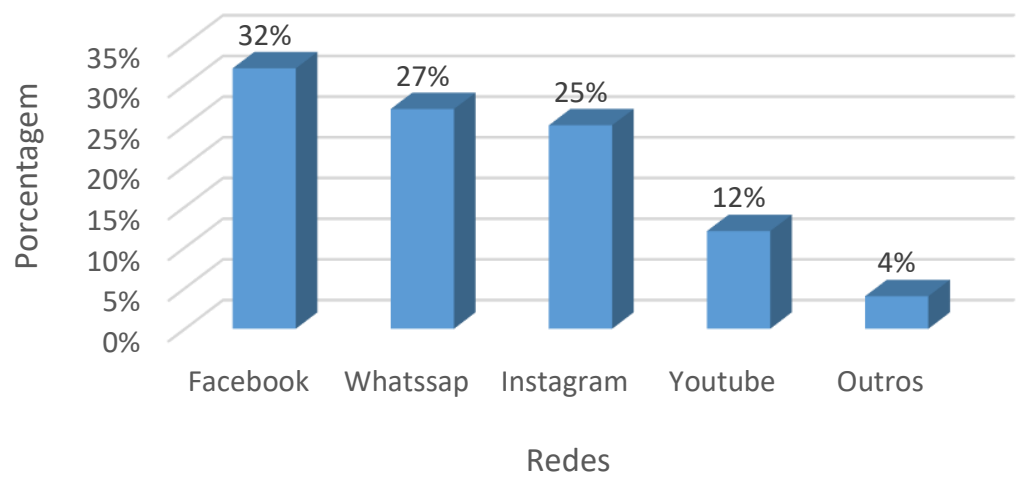

Fonte: Dados da pesquisa.

Eles informaram a rede social ou plataforma mais utilizada quando se conectam à rede internet, (32\%) alegaram utilizar o Facebook que hoje uma das redes sociais mais acessadas do mundo, (27\%) dos investigados afirmaram utilizar com mais frequência o aplicativo de troca de mensagens WhatsApp, já a plataforma de vídeos Youtube é utilizado por (25\%) dos investigados, o Instagram tem um percentual de (12\%) de acesso pelas pessoas, já (4\%) utilizam outra rede ou plataforma diferente das aqui citadas, porém de relevância para o estudo.

Em sequência do contexto apresentado anteriormente, perguntou-se aos investigados a frequência de busca por produtos ou serviços na rede, com o propósito de identificar se os consumidores fazem pesquisas atrás de informações como valores, perfil do produto, dados de serviços antes de efetuar as compras on-line, de acordo como mostrado no gráfico 6.

Gráfico 6 - Frequência de busca por produtos ou serviços na rede

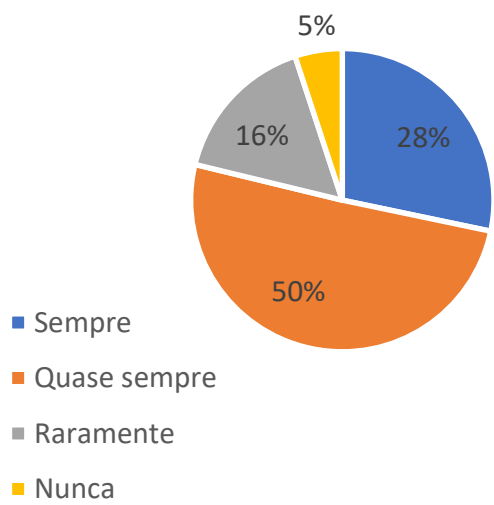

Fonte: Dados da pesquisa. 
Conforme mostrado no gráfico 5, cerca de (50\%) dos consumidores da pesquisa, ou seja, metade dos mesmos, pesquisam quase sempre produtos e serviços na internet. Entre a totalidade dos 50 investigados, (28\%) sempre fazem busca na rede, já (16\%) raramente realizam pesquisas na internet ou lojas virtuais, e por último, apenas (5\%) afirmaram nunca realizar este meio de busca de informações de produtos e serviços. Portanto, compreende-se que de maneira geral as pessoas da amostragem deste estudo em Juazeiro do Norte, costumam recorrentemente e de forma crescente a realização da procura por produtos e serviços na internet, com o intuito de adquirir para os mesmos descontos e praticidade na escolha.

Conforme o exposto, pode-se verificar que a ação do e-commerce inserido na rede no município mencionado tem sido constante e refletindo sobre isso, percebe-se que a necessidade da população ao conhecimento e busca de informações do produto é tão quanto importante ir ao uma loja, já que a rapidez de um clique o usuário recebe e tem acesso à um conjunto de dados do que ele está procurando, podendo fazer tudo isso sem deslocar e em qualquer lugar.

Para se obter uma visão da frequência de acesso a sites distintos e de forma regular pelos usuários em relação ao comércio eletrônico, foi perguntado aos investigados os endereços de buscas por produtos ou serviços mais procurados na internet, com o objetivo de verificar os locais ou sites de acesso mais procurados pelos usuários, conforme o gráfico 7 mostra os resultados.

Gráfico 7 - Endereços de buscas por produtos ou serviços comumente realizados pelos investigados.

\section{Principais locais de buscas de produtos ou serviços}

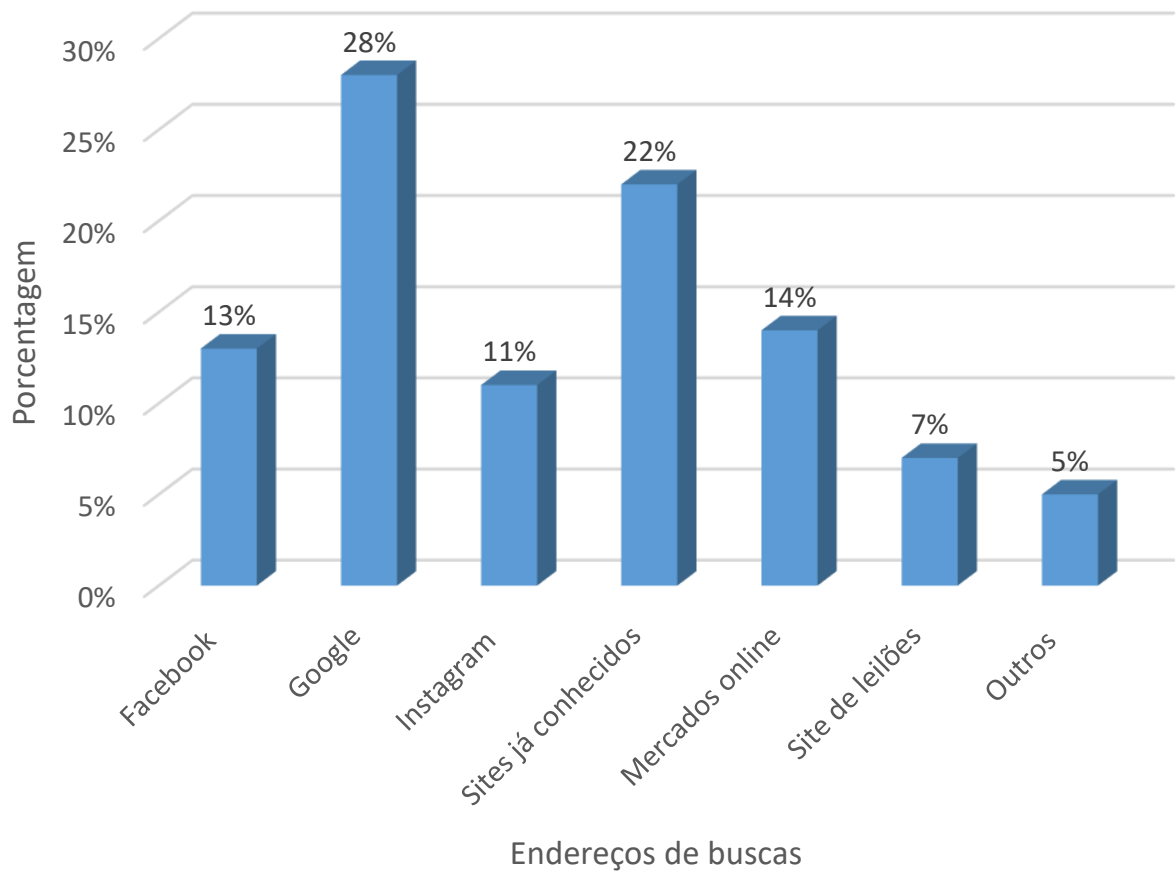

Fonte: Dados da pesquisa. 
De acordo com os dados obtidos, verifica-se que o Google, é o endereço eletrônico mais utilizado pelos consumidores dentre o grupo do presente trabalho, com a margem de (28\%), em seguida vem os sites já conhecidos por eles, com uma porcentagem de (22\%), mercados online com (14\%), Facebook com a marca de (13\%), Instagram atingiu (11\%), sites de leilões (7\%) e somente (5\%) escolheram a opção outros para endereços de procura de produtos ou serviços na rede. É bom analisar esses itens, pois tem-se uma perspectiva da forma que os usuários se comportam frente a diversos meios de procura de produtos, já que há um contingente gigantesco do mundo virtual disponíveis para obter materiais ou adquirir serviços.

Outro ponto importante e necessário para o conhecimento do perfil dos consumidores desta pesquisa foi investigar o ramo de produtos ou serviços mais procurados pelos investigados, na qual foram perguntados sobre essa assertivas, com o objetivo de identificar quais serviços são mais buscados e consequentemente comprados na internet através do comércio eletrônico. Como é apresentado no gráfico 8 .

Gráfico 8 - Ramo de produtos ou serviços mais procurados pelos investigados.

\section{Produtos e serviços mais procurados}

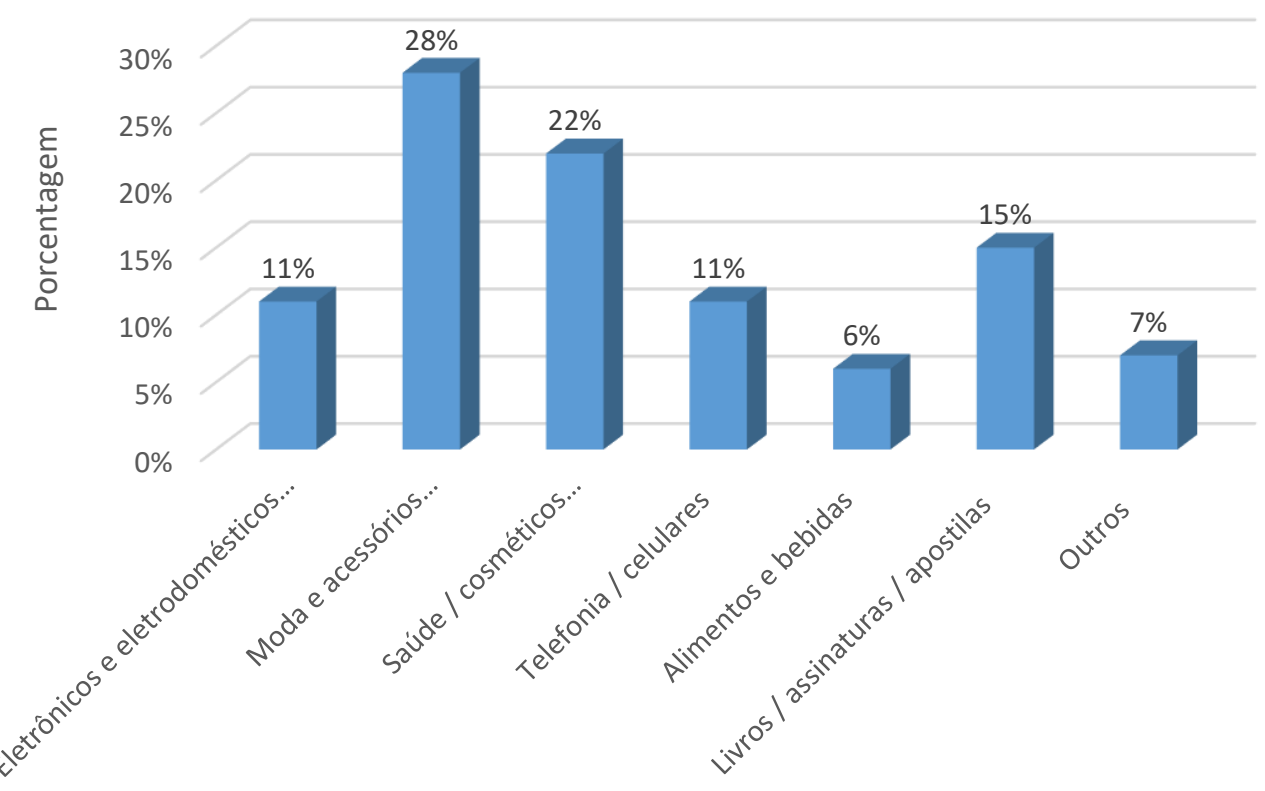

Produtos e serviços

Fonte: Dados da pesquisa.

Quando foi perguntado sobre os produtos ou serviços mais procurados aos investigados da cidade de Juazeiro do Norte, o maior número de procura é direcionado a moda e acessórios com uma margem de (28\%), seguido do ramo saúde e cosméticos com (22\%) dos consumidores, já livros, assinaturas e apostilas atingiu a margem de (15\%), eletrônicos e eletrodomésticos teve um percentual 
de (11\%), apenas (11\%) dos investigados tem intenção de realizar buscas por telefonia e celulares, $(6 \%)$ fazem procura por alimentos e bebidas e somente (7\%) optaram pela opção outros que devem ser outros conteúdos ou bens não citados aqui encontrados na internet. Logo, é possível notar as variedades de buscas dos usuários na internet, isso reflete a maior facilidade de realizar a procura, pois há os meios tecnológicos como os aparelhos celulares e notebooks que auxiliam de forma eficiente este processo, sem contar a disponibilidade do consumidor fazer este processo sem se deslocar até uma loja física.

Um fator relevante que precisa sempre ser levado em consideração é o quesito segurança durante o processo de compra on-line realizado pelo cliente, por isso os investigados foram indagados sobre a frequência que eles se sentem seguros quando realizam compras na internet, com o objetivo de analisar se os mesmos têm segurança na hora de preencher seus dados e informações ao efetuarem compras e também a confiança nas plataformas que fazem essas transações. O gráfico 9 demonstra essa assertiva.

Gráfico 9 - Processo de compra online em relação à segurança pelos investigados

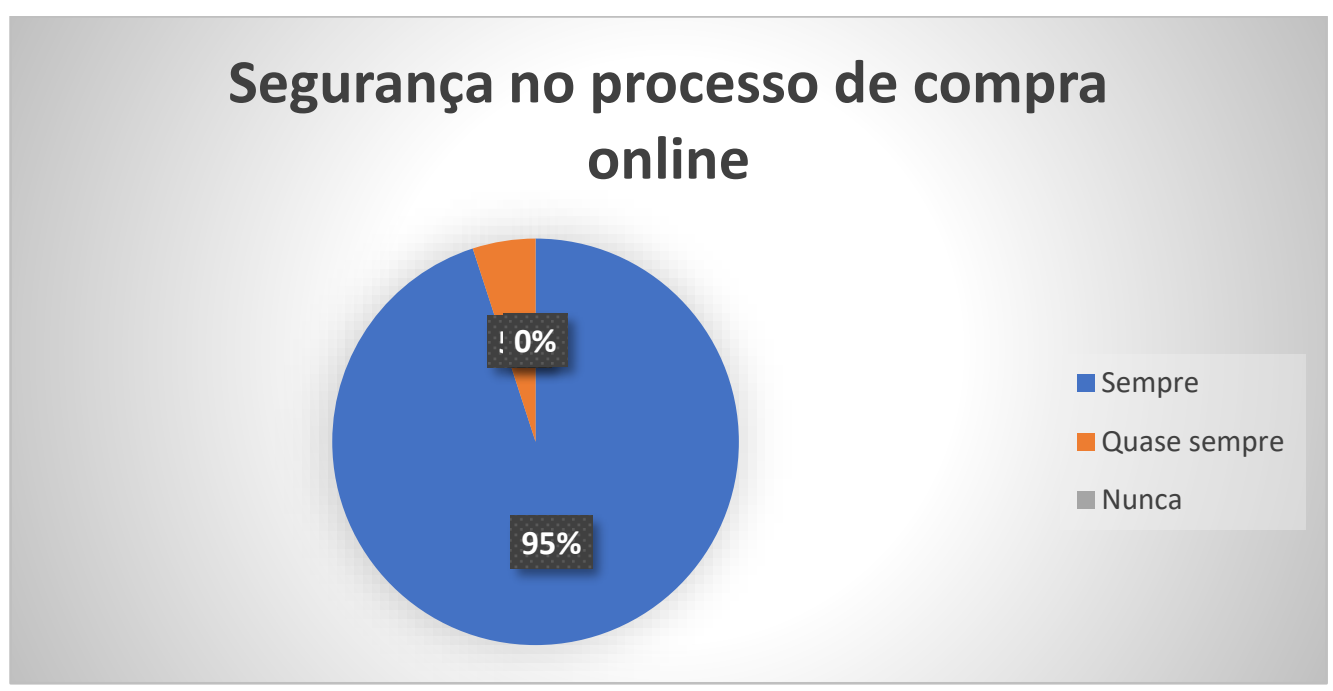

Fonte: Dados da pesquisa.

Sobre como ocorre o processo de compras pelos clientes ou consumidores da cidade de Juazeiro do Norte, dos investigados (95\%) afirmaram que o processo é sempre seguro, enquanto que apenas (5\%) acham o processo quase sempre seguro, para a opção nunca em relação à segurança não houve percentual.

Segundo Cernev e Leite (2005) a segurança é um assunto muito discutido e complexo, pois na internet essa temática não possui uma definição específica e clara, já que é contraposta em relação ao item privacidade, riscos ou relacionado ao conceito confiança de maneira inequívoca. Somado a isso, a presença ou falta de segurança nas comunicações de dados e também das transações eletrônicas fazem parte das restrições mais analisadas e complexas em detrimento da segurança residentes nos sites ou endereços eletrônicos. 
Ainda de acordo com Cernev e Leite (2005) afirmam que a compreensão de segurança dos usuários está relacionada à realização de qualquer transação eletrônica através da internet, especificamente no processo de pagamento. As incertezas ligadas ao recebimento do produto após a aquisição e a confiança nos agentes envolvidos do e-commerce provocam apreensão aos usuários, já que a reputação e histórico de cada envolvido são de extrema importância para os clientes.

No gráfico 10 abaixo, os consumidores foram perguntados sobre a avaliação quando efetuam compras online, essa assertiva tem como objetivo ter uma visão das características do processo de compras, em relação a sua real aplicabilidade e funcionalidade quando utilizado pelo usuário. A avaliação do cliente depende muito da reputação da loja on-line que está revendendo produtos a esse cliente, como também se essa loja dispõe de funcionalidades específicas que atendam ás necessidades e objeções do mesmo, para poder dar condições de manter o processo funcionando ara que o usuário conclua sua compra de forma segura, rápida e sem burocracia. Dessa forma, se tudo ocorrer conforme o consumidor pensa que vai ser em relação a aquisição de um produto sem empecilhos, é vantajoso tanto para quem está vendendo, e mais ainda para a aceitabilidade do comprador.

Gráfico 10 - Avalição dos consumidores quando da realização de compras on-line.

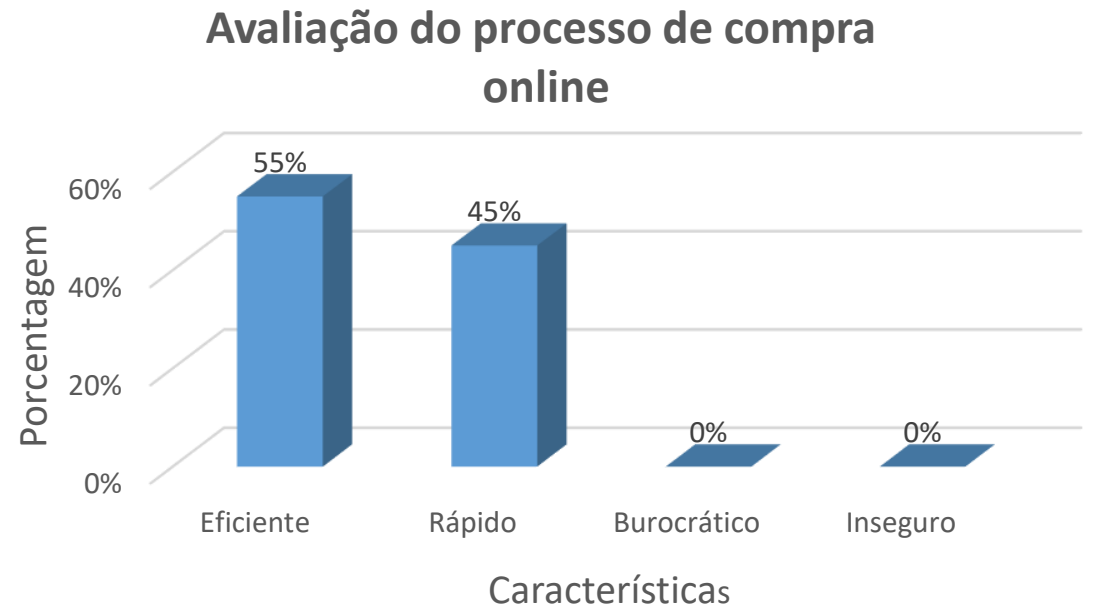

Fonte: Dados da pesquisa.

Em relação a avaliação dos consumidores quando do processo de realização de compras on-line, da amostragem dos 50 consumidores investigados, (55\%) demonstraram que o processo é eficiente, já os outros $(45 \%)$ da totalidade afirmara que o processo é rápido para efetuar uma compra online, que inclui desde o início do processo de compra até o recebimento do produto ao consumidor. Para as opções burocrático e inseguro não houve valorações por partes dos investigados.

Zeithaml e Bitner (2003) afirmam que a definição dos termos "satisfação" e "qualidade em serviço" comumente são confundidos, no entanto, são conceitos fundamentalmente diferentes quanto as suas causas subjacentes e aquilo que produzem como resultado. Apesar de terem algumas coisas em 
comum, a satisfação é visualizada normalmente como um conceito mais geral, ao passo que a determinação da qualidade em serviço se concentra especialmente nas dimensões do serviço. Para tanto, a qualidade vista em serviço é um componente de satisfação do cliente.

Para complementação do processo de compra on-line, perguntou-se os meios de entrega quanto ao recebimento dos produtos adquiridos, pois geralmente há diferentes formas de recebe-los, porém com preços e prazos diferentes, essa assertiva tem como objetivo identificar quais meios de entrega mais utilizados pelos consumidores. O gráfico 11 apresenta está perspectiva obtida dos resultados advindos da pesquisa de campo.

Gráfico 11 - Meios de entrega dos produtos adquiridos na compra on-line.

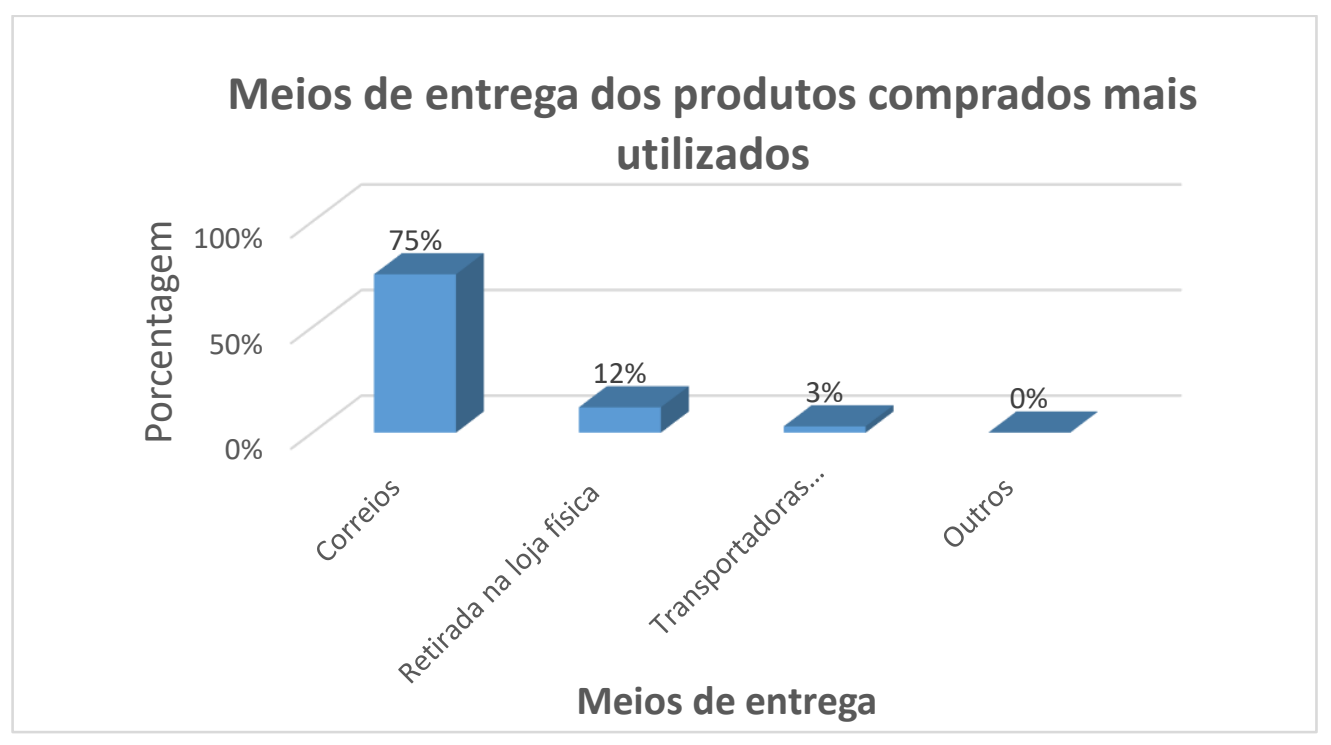

Fonte: Dados da pesquisa.

Como visto no gráfico apresentado, grande parte importante das compras online, são entregues pelo meio Correios, com a margem de (75\%), em seguida tem-se a opção de retirada na loja física, ou seja, o consumidor ou cliente, efetua a compra online, e vai retirar no mesmo dia outro dia adequado na loja física mais próxima em que foi realizada a compra, (3\%) dos investigados optam por receber os produtos através de transportadores privadas, para a opção outros, $(0 \%)$.

Para um entendimento da logística no E-commerce, de acordo com Guasti (2010) é fundamental aos empresários de comércio eletrônico adotarem uma logística nas suas operações, sendo uma forma eficiente para atrair e fidelizar os clientes de suas lojas. Quando um e-consumidor interessado efetua uma compra com prazo de entrega de até um dia útil, certamente o mesmo irá exigir que esse prazo seja cumprido. Do mesmo modo, esperará que a integridade dos produtos não esteja comprometida, com uma boa logística de transporte. Contudo, outro aspecto que deve ter total atenção das empresas é a demanda de pedidos, que de acordo a sazonalidade pode crescer. 
Seguindo esse ínterim, os investigados foram indagados sobre como avaliam o atendimento no processo de compras na internet, com o objetivo de verificar se os consumidores estão tendo suas necessidades atendidas, como também se estão conseguindo finalizar a obtenção de um produto e quando ocorra algum problema possa ter atendimento e manutenção de maneira eficiente e com qualidade. Este é um ponto bastante discutido, por que muitas vezes em alguns sites, o atendimento ao cliente é demorado e as vezes não disponibilizam contatos obrigatórios como telefone ou e-mail, isso faz com que o consumidor não tenha mais interesse em voltar a esse site e ainda fazer uma avaliação negativa nos campos disponíveis do próprio site ou em alguns de reputações.

Gráfico 12 - Avaliação do atendimento ao cliente no processo de compras on-line.

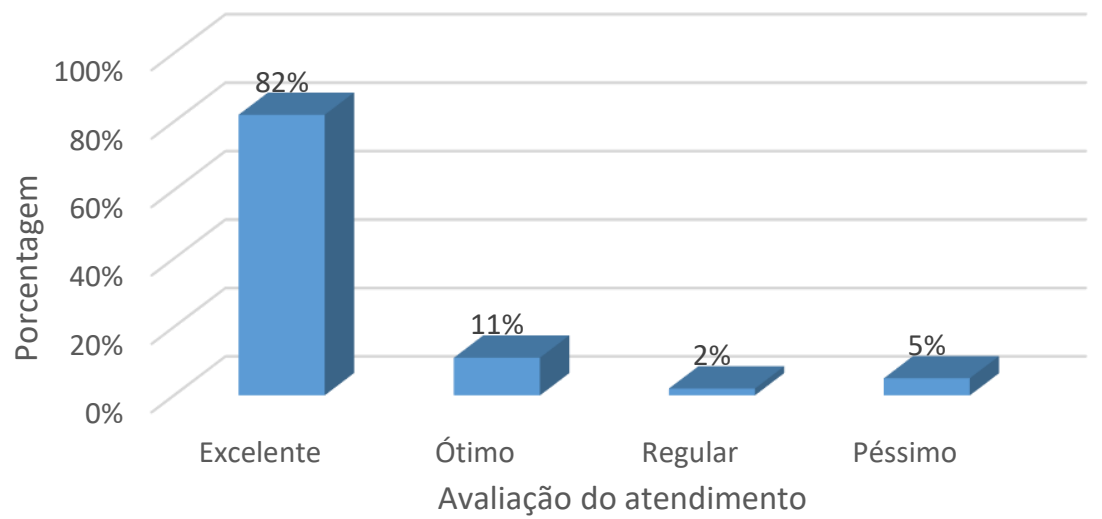

Fonte: Dados da pesquisa.

De acordo com a apresentação dos dados mostrados, (82\%) dos consumidores da pesquisa avaliam o atendimento ao cliente no processo de compras on-line como excelente, enquanto que (11\%) identifica o atendimento como ótimo, (5\%) como péssimo e apenas (2\%) como regular.

Nessa perspectiva de avaliação do processo de compras on-line, é uma forma de analisar as reputações das empresas que trabalham com esse ramo de negócios, pois, mostra uma visão de qual empresa oferece produtos e serviços de qualidade, ou as que oferecem melhores preços, com mais formas de pagamento. Assim, o consumidor, quando realiza uma busca na internet, ele procura produtos que sejam sim, duráveis, com qualidades boas, preços acessíveis, mas também busca, que o processo de compra seja rápido, seguro e sem burocracia, já que a opção de escolher por utilizar as redes para realizar compras é advinda da opção de não se deslocar até uma loja física.

De acordo com Henzer (2013) uma empresa deve acompanhar todos os contatos realizados pelo cliente e ser o mais ágil possível para respondê-lo. A concorrência no e-commerce é grande e se destaca aquela que oferece a melhor experiência de compra para o cliente. Em complemento a isso, a solução de pós-venda deixa claro que o atendimento não termina quando o produto é vendido. 
Rodrigues, Silva e Andrade (2013, p.10) concluem que "o pós-vendas é uma das principais ferramentas para retenção dos clientes, mas para a sua aplicação são necessárias muitas estratégias e tem que se fazer um trabalho planejado e sistematizado para se ter um bom resultado". É mais fácil reter os que já são clientes do que conquistar novo, e por esse motivo uma das estratégias principais que deve ser adotada para se ter melhores resultados é fazer o melhor pós-vendas, entre outras estratégias de marketing.

O consumidor, com sua prática constante de buscar informações e conhecer mais os produtos, assim como verificar preços e outros detalhes, geralmente realiza variadas compras de acordo com mês que tem mais crédito e necessidade de compras online, já que a maioria que utilizam a rede para obter produtos, tendo um padrão de compras por período, assim como uma regularidade. Por isso, para finalizar o questionário, perguntou-se aos consumidores da pesquisa, a quantidade de compras on-line efetuadas em 1 (um) semestre, com o propósito de fazer um quantitativo do volume de compras realizadas pelo grupo da amostragem em 6 (seis) meses.

Gráfico 13 - Quantidade de compras on-line realizadas em um semestre.

\section{Quantidade de compras realizadas semestre}

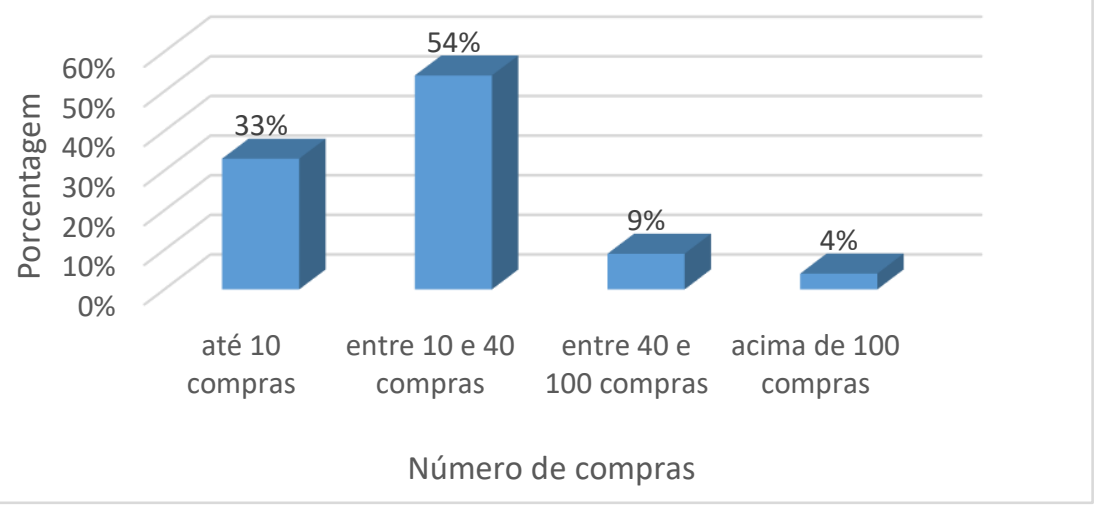

Fonte: Dados da pesquisa.

Com relação a quantidade de compras on-line efetuadas em um semestre, (54\%) dos consumidores da amostragem desta pesquisa afirmam que realizam entre 10 e 40 compras em um semestre, (33\%) realizam até 10 compras on-line para esse período, (9\%) efetuam entre 40 e 100 compras, e apenas (4\%) realizam acima de 100 compras em seis meses.

\section{Considerações Finais}

Esta pesquisa buscou-se, como objetivo geral, formular o entendimento da importância do ecommerce para o processo de compras dos clientes da cidade de Juazeiro do Norte - CE e identificar se 
os consumidores estão aptos a realizar compras on-line. Para que o estudo não se restringisse a parte teórica, foi realizada a coleta de dados junto a uma pesquisa de opinião de uma amostragem de consumidores, adentrando no perfil e conhecendo as características dos mesmos, saber o que mais compram, além de detectar o que mais procuram quando realizam buscas na internet.

Procurou-se também, junto aos entrevistados compreender e se aprofundar sobre como a ferramenta comércio eletrônico beneficia os usuários. Logo, chegou-se a algumas conclusões: o ecommerce é bastante difundido e utilizado pelos consumidores; o perfil e as características dos clientes são diversificados; existem diversos benefícios aos consumidores ao adotarem a utilização do comércio eletrônico para realizarem compras; os usuários estão adaptados e detém de conhecimentos em relação ao processo de transações on-line. Foram também mostrados as diferentes formas e locais de buscas na internet pelos consumidores.

Em relação as limitações deste estudo, é ligada a maneira de obtenção e síntese dos dados, pois, a amostragem foi para um grupo, o que não permite a opinião da totalidade dos resultados da sociedade em geral. Logo, indica-se para realização de pesquisas futuras, a utilização de uma amostragem estratificada, para garantir uma melhor segurança e incidência correta dos resultados.

Outro aspecto que limitou a obtenção de um maior número de dados e opiniões, está relacionado ao instrumento de pesquisa, o questionário. Já que, com a elaboração só com perguntas fechadas, não se permitiu aos consumidores aprofundar-se e mostrar com maiores detalhes as suas avaliações em relação ao processo de compras.

Para tanto, a pesquisa é relevante tanto para uma simples conferência, quanto para um estudo direcionado a sociedade em geral ou ao acadêmico. Por isso, compreende-se que o e-commerce além de ser importante para todo o processo de compras dos clientes é essencial para o crescimento onde atua, no caso na cidade de Juazeiro do Norte - CE, em conjunto os clientes com o comércio eletrônico aumentam o poder econômico do município.

\section{Referências}

ARAUJO, Vanessa, S. E-commerce: Fatores que influenciam a satisfação em compras on-line na percepção dos graduandos de administração da UFSC. Florianópolis: TCC, 2015.

ALBERTIN, A. L. Comércio Eletrônico: Modelo, Aspectos e Contribuições de sua Aplicação. 2. ed. São Paulo: Atlas, 2000.

ANDRADE, Rogério. Guia prático de e-commerce. São Paulo: Angra, 2000.

BOOKS, William T. Vendendo para Nichos de Mercado. São Paulo: Atlas, 1993.

CERNEV, Adrian Kemmer, LEITE, Jaci Corrêa. Segurança na internet. A percepção dos Usuários como Fator de Restrição ao Comércio Eletrônico no Brasil. 2002. 262 f. Dissertação (Mestrado) - Curso de Sistemas de Informação, Departamento de Administração, Fundação Getulio Vargas, São Paulo, 
2005. Disponível em: <http://bibliotecadigital.fgv.br/teses/disponiveis/12/12139/tde-10062013160834/>. Acesso em: 17 set. 2018.

CONRADO ADOLPHO. Sim. Nós podemos mudar o mundo. Disponível em: <http://conrado.com.br/sim-nos-podemos-mudar-o-mundo/>. Acesso em 17 out. 2018.

CONRADO ADOLPHO. Comércio eletrônico e o público alvo. Disponível em: <http://conrado.com.br/comercio-eletronico-e-o-publico-alvo>. Acesso em 17 set. 2018.

DINIZ, Letícia, L. SOUZA, Lívia, G, A. RODRIGUES, Luan, C. FAUSTINI, Marcelo, R. O comércio eletrônico como ferramenta estratégica de vendas para empresas. Lins: III encontro científico e simpósio de educação Unisalesiano, 2011.

E-Bit. Crescimento e faturamento: Disponível em: <http://www.wbitempresa.com.br. > Acesso em 27 ago. 2018.

E-COMMERCE.ORG. Atuações do e-commerce no mercado. Disponível em: <http: //www.wcommerce.org.br>. Acesso em 27 set. 2018.

E-COMMERCE.ORG. Evolução da internet - Como Tudo Começou. Disponível em: <http: //www.w-commerce.org.br/stats.php. > Acesso em 8 out. 2018.

ECOMMERCE NA PRÁTICA. O que é ecommerce? Como funciona? Disponível em: $<$ http://ecommercenapratica.com/author/bruno-de-oliveira/>. Acesso em 12 out. 2018.

ECOMMERCE MASTER. Passo a passo: Saiba como montar um E-commerce do zero! Disponível em: <http://ecommercemaster.com.br/conheca-7-tiposde-e-commerce-e-suas-diferentes-na-pratica/>. Acesso em 4 out. 2018.

ECOMMERCE NEWS. Redes sociais são as novas aliadas do comércio eletrônico. Disponível em: <http://ecommercenews.com.br/artigos/redes-sociais--sao-as-novas-aliadas-do-comercio-eletrônico/>. Acesso em 30 set. 2018.

GC WEBMARKETING. O que é E-commerce? Disponível em: $<$ http://www.gestordeconteudos.com/e-commerce/tabid/3910/Default.aspx. > Acesso em 2 set. 2018.

GONÇALVES, Naiara, T.S. Ferreira, Marta, C.A. O comércio eletrônico (e-commerce): um estudo com consumidores. João Pessoa: Relatos de pesquisas, 2017.

GUASTI, Pedro. E-commerce: uma questão de logística. 2010. Disponível em: <https://empresa.ebit.com.br/imprensa_artigos.asp>. Acesso em: 8 set. 2018.

GUSTAVO, Renan M. CORSI, Maithê. TEIXEIRA, Fernando, C. A importância do e-commerce nas pequenas empresas. Jaguariuna: Monografia, 2015.

HERZER, Anderson. Fidelizando clientes no comércio eletrônico. 2013. Disponível em: $<\mathrm{http} / / /$ ecommercenews.com.br/artigos/cases/fidelizando-clientes-no-comercio-eletronico>. Acesso em: 19 set. 2018.

KOTLER, Philip. Administração de Marketing. 10. Ed. São Paulo: Prentice Hall Brasil, 2000.

KOOTLER, Philip. Princípios de Marketing. Rio de Janeiro: Prentice Hall Brasil, 1999.

LIMEIRA, Tânia M. Vidigal. E-Marketing: O Marketing na internet com Casos Brasileiros. São Paulo: Saraiva, 2000. 
LAMOUNIER, Luciana M. A importância do e-commerce como ferramenta de marketing. Brasília: Monografia, 2010.

MULLER, Vilma, N. E-COMMERCE: Vendas pela internet. Assis: TCC, 2013.

NASCIMENTO, Ribeiro, A. SILVA, Bruna, F. SANTOS, Gisele, G. E-commerce: O melhor caminho no mercado atual. Marília: TCC, 2009.

PATTAT, Tahinan. E-commerce - comportamento do consumidor frente às transações on-line. Santa Rosa: TCC, 2014.

RODRIGUES, Kelly Poliana; SILVA, Leandro Cesar Diniz da; ANDRADE, Alexandre Pires de. UMA ANÁLISE DAS AÇÕES DE PÓS-VENDA COMO ESTRATÉGIA DE FIDELIZAÇÃO. In: CONGRESSO VIRTUAL BRASILEIRO DE ADMINISTRAÇÃO, 8., 2013, São Paulo. Anais.... São Paulo: Convibra, $2013 . \quad$ p. 1120.12 .0 Disponível em: <http://www.convibra.com.br/upload/paper/adm/adm_3038.pdf>. Acesso em: 19 set. 2018.

SOUZA, Carlos, A. PINHEIRO, Marco, A. E-COMMERCE: Um estudo sobre o comportamento dos consumidores da Nerdstore. Palhoça - SC: TCC, 2014.

TREPPER, Charles H. Estratégias de E-commerce. Ed Original. Rio de Janeiro, Campus, 2000.

ZEITHAML, Valarie A.; BITNER, Mary Jo. Marketing de Serviços: A Empresa com Foco no Cliente. Tradução de Martin Albert Haag e Carlos Alberto Silveira Netto Soares. 2. ed. Porto Alegre: Bookman, 2003.

\section{Como citar este artigo (Formato ABNT):}

SILVA, Francisca Alberto da; QUEIROZ, Herminig Everson Matos. A Importância do E-Commerce para o Processo de Compras dos Clientes da Cidade de Juazeiro do Norte. Id on Line Rev.Mult. Psic., 2019, vol.13, n.43, p. 943-966. ISSN: 1981-1179.

Recebido: 01/12/2018;

Aceito: 03/12/2018 